\title{
STRATEGI PENGELOLAAN PERIKANAN GURITA DI KABUPATEN BANGGAI LAUT, PROVINSI SULAWESI TENGAH
}

\section{STRATEGY OF OCTOPUS FISHERY MANAGEMENT IN BANGGAI LAUT REGENCY, CENTRAL SULAWESI PROVINCE}

\author{
Daniel Julianto Tarigan ${ }^{1}$, Domu Simbolon ${ }^{2}$, Budy Wiryawan ${ }^{2}$ \\ ${ }^{1}$ Program Studi Teknologi Perikanan Laut, \\ ${ }^{2}$ Depertemen Pemanfaatan Sumberdaya Perikanan, \\ Fakultas Perikanan dan Ilmu Kelautan, Institut Pertanian Bogor \\ Korespondensi: danieljuliantoo@gmail.com
}

\begin{abstract}
Octopus fishery in Banggai Laut Regency is a fisheries small scale fisheries category. This is because Banggai Laut fishermen catch the octopus by using simple ships and fishing gear. Trend CPUE octopus in the last 3 years (20142016) shows a drastic decline. The decline that occurred indicates that the level of utilization of octopus fishing areas in the area has occurred over catching. This shows that octopus in Banggai Laut Regency has not been managed optimally. Management only makes continuous arrests without considering the impact on octopus resources. Proper management needs to maintain the potential of octopus resources to be sustainable. This study aims to formulate the management strategy of octopus fishing area in Banggai Laut Regency. Management strategy using strategy approach Strength, Weakness, Oppurtunity, Threats (SWOT). The management strategy of octopus fishery in Banggai Laut Regency were done by 1) SO Strategy with strategic option: Development of cooperation with fish processing industry and utilizing octopus fishery potential 2) ST strategy with strategic option: Setting strict rules and sanctions related to fisherman who do illegal fishing and limiting the fishing fleet. 3) WO strategy with strategic options: improving human resource quality and building a fishery port. 4) WT strategy with strategic options: make rules related to octopus weight and supervision of fishing grounds.
\end{abstract}

Keyword: Banggai Laut, management, octopus, SWOT

\begin{abstract}
ABSTRAK
Perikanan gurita di Kabupaten Banggai Laut termasuk kategori perikanan yang small scale fisheries. Hal ini dikarenakan nelayan Banggai Laut menangkap gurita dengan menggunakan kapal dan alat tangkap yang sederhana. Tren CPUE gurita dalam 3 tahun terakhir (2014-2016) menunjukkan penurunan yang cukup drastis. Penurunan yang terjadi mengindikasikan bahwa tingkat pemanfaatan daerah penangkapan gurita di daerah tersebut sudah terjadi penangkapan yang berlebih. Hal ini menunjukkan bahwa gurita di Kabupaten Banggai Laut belum dikelola secara optimal. Pengelolaan hanya melakukan penangkapan terus menerus tanpa mempertimbangkan dampak terhadap sumberdaya gurita. Pengelolaan secara benar perlu dilakukan untuk menjaga potensi sumberdaya gurita agar tetap lestari. Penelitian ini bertujuan untuk merumuskan strategi pengelolaan daerah penangkapan octopus di Kabupaten Banggai Laut. Pendekatan strategi pengelolaan menggunakan pendekatan strategi Strength, Weakness, Oppurtunity, Threats (SWOT). Strategi pengelolaan perikanan gurita di Kabupaten Banggai Laut dilakukan dengan 1) Strategi SO dengan opsi strategi: Pengembangan kerjasama dengan industri pengolahan ikan dan memanfaatkan potensi perikanan gurita 2) Strategi ST dengan opsi strategi: Menetapkan aturan dan sanksi yang tegas terkait nelayan yang melakukan illegal fishing dan membatasi armada penangkapan ikan. 3) Strategi WO dengan opsi strategi: peningkatan kualitas SDM dan membangun pelabuhan perikanan. 4) Strategi WT dengan opsi strategi: membuat aturan terkait bobot gurita dan pengawasan daerah penangkapan ikan.
\end{abstract}

Kata kunci: Banggai Laut, gurita, pengelolaan, SWOT 


\section{PENDAHULUAN}

Perikanan gurita di Kabupaten Banggai Laut termasuk kategori perikanan yang small scale fisheries. Hal ini dikarenakan nelayan Banggai Laut menangkap gurita dengan menggunakan kapal dan alat tangkap yang sederhana. Nelayan skala kecil dicirikan dengan berbagai keterbatasan diantaranya adalah keterbatasan waktu untuk melaut, jenis kapal atau alat tangkap yang digunakan (Salas et al. 2004). Nelayan Kabupaten Banggai Laut menangkap gurita dengan menggunakan pancing ulur. Armada penangkapan yang digunakan untuk mengoperasikan pancing ulur juga sederhana, yaitu dengan kapal berukuran $<5$ GT.

Pancing ulur merupakan alat tangkap yang sederhana, selektif terhadap ukuran sumberdaya, ramah lingkungan, mudah mengoperasikan, biaya pembuatan murah dan hasil tangkapan umumnya berkualitas (Nurdin dan Nugraha 2008; Sulistyaningsih et al. 2011). Alat tangkap pancing ulur tersebut menggunakan umpan buatan yang dinamakan cipo dan manis. umpan buatan manis. Umpan buatan cipo terbuat dari bahan kayu yang didalam nya berisi timah. Cipo didasarkan pada bentuk makanan gurita, seperti lobster, kepiting dan udang. Hal ini membuat gurita mudah untuk keluar dari lubang terumbu karang dan mengikuti pergerakan dari alat tangkap dengan umpan buatan cipo, sehingga mudah untuk melakukan penangkapan. Keunggulan dari cipo yaitu dapat digunakan dalam keadaan arus yang kencang, keadaaran perairan yang cukup dalam, dan pada kondisi perairan yang cukup keruh, nelayan tidak perlu melihat langsung ke dasar perairan tempat dimana gurita bersembunyi. Sedangkan umpan buatan manis juga terbuat dari bahan kayu yang didalam nya berisi timah. Umpan buatan manis hanya berbentuk mirip seperti gurita. Hal ini dilakukan agar menarik perhatian dari gurita untuk keluar dari sarang atau bebatuan tempat gurita bersembunyi. Operasi penangkapan menggunakan umpan buatan manis membutuhkan alat bantu penangkapan lainnya, seperti masker. Masker digunakan untuk melihat ke dasar laut dimana tempat gurita bersembunyi.

Tren CPUE gurita dalam 3 tahun terakhir (2014-2016) menunjukkan penurunan yang cukup drastis. Penurunan yang terjadi mengindikasikan bahwa tingkat pemanfaatan daerah penangkapan gurita di daerah tersebut sudah terjadi penangkapan yang berlebih. Hal ini menunjukkan bahwa gurita di Kabupaten Banggai Laut belum dikelola secara optimal. Pengelolaan hanya melakukan penangkapan terus menerus tanpa mempertimbangkan dampak terhadap sumberdaya gurita. Pengelolaan secara benar perlu dilakukan untuk menjaga potensi sumberdaya gurita agar tetap lestari. Pengelolaan perikanan gurita di Kabupaten Banggai Laut dilakukan dengan menggunakan pendekatan SWOT.

Penelitian menggunakan pendekatan SWOT sudah banyak yang melakukan diantaranya formulasi strategi pengembangan pelabuhan perikanan nusantara Pengambengan Jembrana (Suherman 2011), strategi pengembangan pemasaran ikan sidat di unit pengelolaan perikanan budidaya Desa Deket, Kecamatan Deket, Kabupaten Lamongan, Jawa Timur (Bachtiar et al. 2013) dan analisis pengembangan perikanan tangkap di Kota Bengkulu (Suyedi 2007). Namun penelitian tentang pengelolaan perikanan gurita di Kabupaten Banggai Laut belum ada yang melakukan. Oleh karena itu penelitian ini perlu untuk dilakukan. Penelitian ini bertujuan untuk merumuskan strategi pengelolaan daerah penangkapan octopus di Kabupaten Banggai Laut.

\section{METODE PENELITIAN}

Penelitian dilaksanakan pada bulan September-Oktober 2017 di Kabupaten Banggai Laut, Provinsi Sulawesi Tengah. Jenis data yang digunakan adalah data primer dan data sekunder. Data primer yang dibutuhkan terkait aspek sumberdaya gurita, teknologi penangkapan, sosial, ekonomi dan kelembagaan. Data primer diperoleh melalui wawancara mendalam (in-depth interview) dan pengamatan langsung di lapang. Wawancara mendalam adalah suatu proses untuk mendapatkan informasi terkait dengan kepentingan penelitian dengan cara dialog antara peneliti sebagai pewawancara dengan informan atau yang member informasi dalam konteks observasi partisipasi Satori dan Komariah (2009). Wawancara dilakukan secara terstruktur menggunakan daftar pertanyaan (kuesioner). Jumlah responden yang digunakan pada penelitian ini adalah 10 orang yang meliputi 3 nelayan, 4 pegawai Dinas Kelautan dan Perikanan Kabupaten Banggai Laut, 2 pegawai Badan Karantina dan Keamanan Badan Karantina 
Ikan, Pengendalian Mutu dan Keamanan Hasil Perikanan (BKIPM), dan 1 pegawai Pengawas Sumberdaya Kelautan dan Perikanan (PSDKP). Responden yang dipilih ditentukan dengan menggunakan teknik purposive sampling. Menurut Arikunto 2009, purposive sampling adalah metode sampling yang digunakan oleh peneliti jika peneliti mempunyai pertimbanganpertimbangan tertentu dalam pengambilan sampelnya. Pertimbangan karakteristik sampel didasarkan pada data responden yang homogen yaitu armada penangkapan pancing ulur di Kabupaten Banggai Laut. Pemilihan responden ditentukan berdasarkan jawaban responden sesuai keahlian dan pengetahuan yang dimiliki. Pendekatan ini diharapkan mempermudah peneliti untuk menentukan responden yang potensial dengan beberapa kriteria yang sudah ditentukan.

Data sekunder diperoleh dari stakeholder perikanan, diantaranya Dinas Kelautan dan Perikanan Kabupaten Banggai Laut, Badan Karantina Ikan, Pengendalian Mutu dan Keamanan Hasil Perikanan (BKIPM) Banggai Laut, dan Pengawas Sumberdaya Kelautan dan Perikanan (PSDKP) Banggai Laut. Data yang dikumpulkan meliputi, data produksi hasil tangkapan gurita, data jumlah armada perikanan pancing ulur, data pelanggaran, data peraturan pemerintah pusat dan daerah terkait dengan perikanan gurita.

Strategi pengelolaan perikanan gurita di Kabupaten Banggai Laut dianalisis menggunakan pendekatan SWOT. SWOT merupakan analisis yang banyak digunakan para perencana strategis daerah (strategic planner). Metode ini digunakan dalam menghasilkan suatu perencanaan strategis pengembangan daerah. Analisis SWOT didasarkan pada logika yang dapat memaksimalkan kekuatan (strengths) dan peluang (opportunities), namun secara bersamaan dapat meminimalkan kelemahan (weaknesses) dan ancaman (threats). Matriks SWOT dapat digambarkan sebagaimana hasil identifikasi dan perhitungan. Hasil identifikasi dan perhitungan diperoleh dengan menggunakan analisa IFAS (Internal Factor Analysis Summary) dan EFAS (External Factor Analysis Summary). Analisis IFAS digunakan untuk memanfaatkan kekuatan yang dimiliki dalam strategi pengelolaan perikanan gurita di Kabupaten Banggai Laut. Analisis EFAS digunakan untuk melihat peluang yang dapat dimanfaatkan untuk pengelolaan perikanan gurita, serta persiapan menghadapi atau mengurangi ancaman yang akan terjadi. Adapun langkah untuk melakukan analisis SWOT adalah sebagai berikut (Rangkuti 2009):

1. Menentukan faktor-faktor kelemahan dan kekuatan, serta faktor peluang dan ancaman.

2. Memberi bobot pada masing-masing faktor tersebut dengan skala mulai dari 1,00 (paling penting) sampai dengan 0.00 (tidak penting), berdasarkan pengaruh faktor tersebut terhadap posisi strategis instansi. Jumlah bobot tidak boleh lebih dari skor total 1.00 .

3. Memberi rating untuk masing-masing faktor dengan menggunakan skala mulai dari 4 (sangat baik) sampai dengan 1 (di bawah rata-rata).

4. Mengalikan bobot dan rating untuk menentukan skor tiap-tiap faktor.

5. Menjumlahkan skor pembobotan untuk memperoleh total skor pembobotan. Berdasarkan total skor dari masingmasing kriteria S-W-O-T, digunakan dalam penggambaran posisinya pada Tabel IFAS dan EFAS (Tabel 1 dan 2).

Tahap pengambilan keputusan matrik SWOT diperoleh dengan menggunakan matriks internal dan matriks eksternal dengan melakukan pembobotan faktor internal dan eksternal. Kuadran tersebut adalah kuadran I, II, III, IV, V, VI, VII, VIII, dan IX (Gambar 1). Kuadran I menunjukkan pengelolaan dalam pertumbuhan dengan konsentrasi pada integrasi vertikal. Kuadran II menunjukkan pertumbuhan dengan konsentrasi pada integrasi horizontal. Kuadran III menunjukkan pengelolaan dalam kondisi penciutan atau turnaround. Kuadran IV menunjukkan pengelolaan dalam kondisi stabilitas. Kuadran V menunjukkan pengelolaan dalam kondisi pertumbuhan dengan konsentrasi pada integrasi horizontal atau stabilitas. Kuadran VI menunjukkan pengelolaan dalam kondisi divestasi atau pengurangan. Kuadran VII menunjukkan pengelolaan dalam kondisi pertumbuhan melalui diversifikasi konsentrik. Kuadran VIII menunjukkan pengelolaan dalam kondisi pertumbuhan melalui konsentrasi konglomerasi dan kuadran IX menunjukkan pengelolaan dalam kondisi likuidasi. 
Tabel 1. Tabulasi IFAS

\begin{tabular}{|c|c|c|c|}
\hline Faktor Internal & Bobot (B) & Rating (R) & Skor \\
\hline \multicolumn{4}{|l|}{ Kekuatan (S) } \\
\hline \multicolumn{4}{|l|}{$\mathrm{S} 1$} \\
\hline \multicolumn{4}{|l|}{$\ldots \mathrm{Sn}$} \\
\hline \multicolumn{4}{|l|}{ Kelemahan (W) } \\
\hline \multicolumn{4}{|l|}{ W1 } \\
\hline \multicolumn{4}{|l|}{$\ldots \mathrm{Wn}$} \\
\hline Total IFAS & & & \\
\hline
\end{tabular}

Tabel 2. Tabulasi EFAS

\begin{tabular}{llll}
\hline \multicolumn{1}{c}{ Faktor Internal } & Bobot (B) & Rating (R) & Skor \\
\hline Peluang $(\mathrm{O})$ O1. & & \\
\\
... On & & \\
\hline
\end{tabular}

Ancaman (T)

$\mathrm{T} 1$.

... Tn

Total EFAS

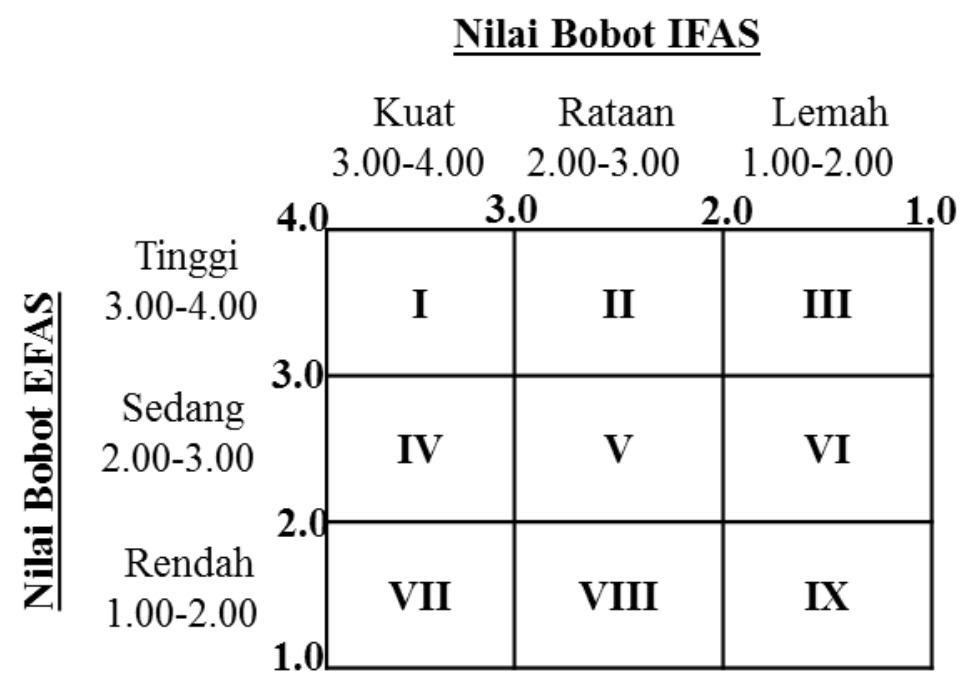

Gambar 1. Skematis Analisis SWOT

Matriks SWOT dapatmenggambarkan secara jelas berbagai peluang dan ancaman eksternal yang dihadapi instansi dapat disesuaikan dengan kekuatan dan kelemahan yang dimilikinya (Tabel 3). Matriks ini dapat berbagai peluang, berbagai ancaman, kelemahan internal, dan kekuatan internal yang menghasilkan empat set kemungkinan alternatif strategi. Salah satu dari empat set kemungkinan alternatif strategis yang diharapkan dari analisis SWOT untuk digunakan dalam strategi suatu strategi pengelolaan. Empat set alternatif strategis yang dihasilkan dari matriks SWOT adalah sebagai berikut:

1. Strategi SO: Strategi ini dibuat dengan memanfaatkan seluruh kekuatan untuk merebut dan memanfaatkan peluang yang sebesar-besarnya.

2. Strategi ST: Merupakan strategi yang 
menggunakan kekuatan yang dimiliki untuk mengatasi ancaman.

3. Strategi WO: Strategi ini dimanfaatkan berdasarkan pemanfaatan peluang yang ada dengan meminimalkan kelemahan yang ada.
4. Strategi WT: Strategi ini didasarkan pada kegiatan yang bersifat defensif dan berusaha meminimalkan kelemahan yang ada serta menghindari ancaman. Strategi pengelolaan disajikan pada Tabel 3.

Tabel 3. Matriks SWOT

\begin{tabular}{|c|c|c|}
\hline IFAS & \begin{tabular}{l}
\multicolumn{1}{c}{ Strength (S) } \\
Tentukan faktor-faktor \\
kekuatan internal
\end{tabular} & $\begin{array}{l}\text { Weaknesses (W) } \\
\text { Tentukan faktor-faktor } \\
\text { kelemahan internal }\end{array}$ \\
\hline $\begin{array}{l}\text { Opportunies (0) } \\
\text { Tentukan faktor-faktor } \\
\text { peluang eksternal }\end{array}$ & $\begin{array}{l}\text { Strategi - SO } \\
\text { Ciptakan strategi yang } \\
\text { menggunakan kekuatan untuk } \\
\text { memanfaatkan peluang }\end{array}$ & $\begin{array}{l}\text { Strategi - WO } \\
\text { Ciptakan strategi yang } \\
\text { meminimalkan kelemahan } \\
\text { untuk memanfaatkan peluang }\end{array}$ \\
\hline $\begin{array}{l}\text { Treaths } \mathbf{( T )} \\
\text { Tentukan faktor-faktor } \\
\text { ancaman eksternal }\end{array}$ & $\begin{array}{l}\text { Strategi - ST } \\
\text { Ciptakan strategi yang } \\
\text { menggunakan kekuatan untuk } \\
\text { mengatasi ancaman }\end{array}$ & $\begin{array}{l}\text { Strategi - WT } \\
\text { Ciptakan strategi yang } \\
\text { meminimalkan kelemahan } \\
\text { dan menghindari ancaman }\end{array}$ \\
\hline
\end{tabular}

\section{HASIL DAN PEMBAHASAN}

\section{Faktor Strategi Internal di Kabupaten Banggai Laut}

Faktor internal yang perlu dipertimbangkan dalam pengelolaan perikanan gurita di Kabupaten Banggai Laut adalah kekuatan dan kelemahan yang teridentifikasi. Kekuatan yang dimaksudkan adalah gurita merupakan salah satu hasil tangkapan dominan yang terdapat di Kabupaten Banggai Laut, perikanan dan kelautan telah memberikan kontribusi ekonomi bagi pembangunan daerah Kabupaten Banggai Laut, armada penangkapan gurita yang ramah lingkungan, dukungan dan komitmen pemerintah terhadap perikanan dan kelautan dan biaya operasional melaut yang rendah. Kelemahan yang teridentifikasi dalam pengelolaan perikanan gurita di Kabupaten Banggai Laut adalah kapal dan alat tangkap yang masih tradisional, sumberdaya atau tenaga ahli perikanan yang masih sedikit, masih minimnya koordinasi dan pengawasan yang dilakukan terhadap nelayan skala kecil, belum tersedianya pelabuhan perikanan di daerah Kabupaten Banggai Laut. Bobot dari masing-masing kekuatan dan kelemahan tersebut disajikan pada Tabel 4.

Gurita termasuk salah satu hasil tangkapan dominan yang terdapat di Kabupaten Banggai Laut. Hasil olahan penelitian menunjukkan hasil tangkapan gurita sebesar $16 \%$ dari total komposisi hasil tangkapan ikan secara keseluruhan di Kabupaten Banggai Laut. Pada tahun 2016, produksi gurita mengalami kenaikan $72 \%$ yaitu 8.076 ton/tahun dibanding dengan produksi tahun 2015 yang hanya sebanyak 1.961 ton/tahun (Skor: 0.39). Nelayan Kabupaten Banggai Laut melakukan operasi penangkapan dengan biaya bekal melaut yang rendah. Berdasarkan hasil wawancara, nelayan hanya menghabiskan biaya sebesar Rp 30.000 - Rp 50.000 untuk melaut (Skor: 0.30). Nelayan gurita Kabupaten Banggai Laut menggunakan armada penangkapan dan alat tangkap yang sederhana. Armada penangkapan dibawah <5 GT. Alat tangkap yang digunakan hanya pancing ulur dengan umpan buatan cipo dan manis. Hal ini menunjukkan bahwa nelayan melakukan penangkapan dengan menggunakan armada penangkapan skala kecil (Skor: 0.30). Berdasarkan wawancara terdapat 4 perusahaan yang mengelola perikanan gurita ekspor di Kabupaten Banggai Laut. Harga gurita di Kabupaten Banggai Laut cukup tinggi yaitu sebesar Rp $52.000 / \mathrm{kg}$ (Skor: 0.40).

Kapal dan alat tangkap yang digunakan nelayan Kabupaten Banggai Laut masih tradisional (Skor: 0.20). Berdasarkan wawancara, nelayan hanya melakukan penangkapan gurita di sekitar perairan Banggai Laut. Hal ini dikarenakan terbatasnya kemampuan armada penangkapan untuk menjangkau daerah penangkapan yang lebih jauh. Terbatasnya tenaga ahli perikanan dari segi jumlah dan 
pengetahuan di Kabupaten Banggai Laut (Skor: 0.26). Hal ini menyebabkan minimnya koordinasi dan pengawasan yang dilakukan terhadap nelayan skala kecil di Kabupaten Banggai Laut (Skor: 0.26). Selain itu, Kabupaten Banggai Laut belum memiliki pelabuhan khusus perikanan (Skor: 0.22).

Tabel 4 matriks Internal Factor Analysis Summary (IFAS) menunjukkan bahwa faktor kekuatan dengan skor 1.69 lebih tinggi dibandingkan dengan faktor kelemahan dengan skor 0.94. Hal ini menunjukkan faktor kekuatan memiliki tingkat kepentingan yang lebih tinggi untuk strategi pengelolaan. Hasil analisis keseluruhan menunjukkan strategi pengelolaan perikanan gurita di Kabupaten Banggai Laut berada pada skor 2.63. David (2004) menyebutkan bahwa skor permbobotan $>2.5$ tergolong kuat dan $<2.5$ tergolong lemah. Hal ini menunjukkan bahwa faktor internal tergolong kuat. Kondisi internal ini menunjukkan bahwa pengelolaan perikanan gurita memiliki kekuatan untuk mengatasi situasi. Kondisi perikanan gurita yang ada sudah mampu mengatasi kelemahan dengan memanfaatkan kekuatan yang dimiliki.

Tabel 4. Hasil Tabulasi IFAS

\begin{tabular}{|c|c|c|c|c|}
\hline No & Faktor Internal & Bobot (B) & Rating (R) & Skor (BxR) \\
\hline & Kekuatan & & & \\
\hline 1 & $\begin{array}{l}\text { Gurita termasuk hasil tangkapan dominan yang } \\
\text { terdapat di Kabupaten Banggai Laut }\end{array}$ & 0.13 & 3 & 0.39 \\
\hline 2 & $\begin{array}{l}\text { Perikanan dan kelautan telah memberikan } \\
\text { kontribusi ekonomi bagi pembangunan daerah } \\
\text { Kabupaten Banggai Laut }\end{array}$ & 0.10 & 3 & 0.30 \\
\hline 3 & $\begin{array}{l}\text { Armada penangkapan pancing ulur termasuk } \\
\text { skala kecil }\end{array}$ & 0.10 & 3 & 0.30 \\
\hline 4 & Harga gurita yang termasuk ekonomis tinggi & 0.10 & 4 & 0.40 \\
\hline \multirow[t]{3}{*}{5} & Biaya bekal melaut yang rendah & 0.10 & 3 & 0.30 \\
\hline & Jumlah & 0.53 & & 1.69 \\
\hline & Kelemahan & & & \\
\hline 1 & Kapal dan alat tangkap yang masih tradisional & 0.10 & 2 & 0.20 \\
\hline 2 & $\begin{array}{l}\text { Sumberdaya atau tenaga ahli perikanan yang } \\
\text { masih sedikit }\end{array}$ & 0.13 & 2 & 0.26 \\
\hline 3 & $\begin{array}{l}\text { Masih minimnya koordinasi dan pengawasan } \\
\text { yang dilakukan terhadap nelayan skala kecil }\end{array}$ & 0.13 & 2 & 0.26 \\
\hline \multirow[t]{3}{*}{4} & $\begin{array}{l}\text { Belum tersedianya pelabuhan perikanan di } \\
\text { daerah Kabupaten Banggai Laut }\end{array}$ & 0.11 & 2 & 0.22 \\
\hline & Jumlah & 0.47 & & 0.94 \\
\hline & Total & 1 & & 2.63 \\
\hline
\end{tabular}

\section{Faktor Strategi Eksternal di Kabupaten} Banggai Laut
Faktor eksternal yang perlu dipertimbangkan dalam pengelolaan perikanan gurita di Kabupaten Banggai Laut adalah peluang dan ancaman yang teridentifikasi. Peluang yang dimaksudkan adalah adanya perusahaan pengolahan ekspor gurita di Kabupaten Banggai Laut, potensi sumberdaya gurita yang melimpah di Perairan Banggai Laut, dukungan dan komitmen pemerintah daerah Banggai Laut terhadap sektor perikanan dan kelautan, dan pengembangan perikanan

gurita akan membuka peluang kesempatan kerja di bidang perikanan. Ancaman yang akan terjadi di Kabupaten Banggai Laut dikarenakan masih kurangnya informasi dan pemahaman nelayan terkait pengelolaan sumberdaya gurita, masih ditemukannya nelayan yang menggunakan bom dan racun dalam operasi penangkapan, tren ukuran gurita yang tertangkap semakin kecil, tingginya tekanan dan upaya penangkapan gurita, konflik kepentingan yang terjadi dalam zonasi daerah penangkapan. Bobot dari masing-masing peluang dan ancaman tersebut disajikan pada Tabel 5.

Potensi perikanan gurita di 
Kabupaten Banggai Laut cukup melimpah yaitu 10.652 ton/tahun (Skor: 0.42). Potensi yang cukup melimpah membuat adanya investor yang tertarik untuk membuat perusahaan pengolahan ekspor gurita di Kabupaten Banggai Laut (Skor: 0.36). Dukungan dan komitmen pemerintah Banggai Laut terhadap sektor perikanan dan kelautan (Skor: 0.32). Oleh karena itu, pengelolaan perikanan gurita akan membuka peluang kesempatan kerja untuk masyarakat sekitar Kabupaten Banggai Laut (Skor: 0.32).

Informasi dan pemahaman nelayan dalam pengelolaan gurita masih minim (Skor: 0.28). Hal ini dikarenakan masih ditemukannya nelayan Kabupaten Banggai Laut yang melakukan operasi penangkapan masih menggunakan bom atau racun (Skor: 0.22). Berdasarkan wawancara tren ukuran gurita yang tertangkap oleh nelayan dari tahun ke tahun semakin kecil (Skor: 0.20). $\mathrm{Hal}$ ini dikarenakan tingginya tekanan dan upaya penangkapan gurita di Kabupaten Banggai Laut (Skor: 0.20). Selain itu, masih ditemukannya nelayan non lokal yang menangkap gurita di Kabupaten Banggai
Laut. Nelayan non lokal yang menangkap gurita dikarenakan sudah terbiasa melakukan penangkapan di Perairan Kabupaten Banggai Laut. Hal ini berpotensi terjadinya konflik daerah penangkapan gurita di kemudian hari (Skor: 0.16).

Tabel 5 memperlihatkan matriks External Factors Analysis Summary (EFAS). Matriks EFAS menunjukkan fakor peluang dengan skor 1.42 lebih tinggi dibandingkan dengan faktor ancaman dengan skor 1.06. Berdasarkan hasil tersebut dapat disimpulkan bahwa strategi peluang masih mendominasi untuk perikanan gurita di Kabupaten Banggai Laut. Secara keseluruhan hasil analisis menunjukkan bahwa strategi pengelolaan perikanan gurita di Kabupaten Banggai Laut memiliki skor 2.47. Skor permbobotan $>2.5$ tergolong kuat dan $<2.5$ tergolong lemah (David 2004). Hal ini menunjukkan bahwa faktor eksternal di Kabupaten Banggai Laut masih tergolong lemah. Kondisi ini membutuhkan peningkatan pengelolaan perikanan gurita di Kabupaten Banggai Laut untuk mengatasi ancaman dengan memanfaatkan peluang yang dimiliki.

Tabel 5. Hasil Tabulasi EFAS

\begin{tabular}{|c|c|c|c|c|}
\hline No & Faktor Internal & Bobot (B) & Rating (R) & Skor (BxR) \\
\hline & Peluang & & & \\
\hline 1 & $\begin{array}{l}\text { Adanya perusahaan pengolahan ekspor gurita di } \\
\text { Kabupaten Banggai Laut }\end{array}$ & 0.12 & 3 & 0.36 \\
\hline 2 & $\begin{array}{l}\text { Potensi sumberdaya gurita yang melimpah di } \\
\text { Perairan Banggai Laut }\end{array}$ & 0.14 & 3 & 0.42 \\
\hline 3 & $\begin{array}{l}\text { Dukungan dan komitmen pemerintah daerah } \\
\text { Banggai Laut terhadap sektor perikanan dan ke- } \\
\text { lautan }\end{array}$ & 0.11 & 3 & 0.33 \\
\hline \multirow[t]{3}{*}{4} & $\begin{array}{l}\text { Pengembangan perikanan gurita akan membuka } \\
\text { peluang kesempatan kerja di bidang perikanan }\end{array}$ & 0.10 & 3 & 0.30 \\
\hline & Jumlah & 0.47 & & 1.42 \\
\hline & Ancaman & & & \\
\hline 1 & $\begin{array}{l}\text { Masih kurangnya informasi dan pemahaman } \\
\text { nelayan terkait pengelolaan sumberdaya gurita }\end{array}$ & 0.14 & 2 & 0.28 \\
\hline 2 & $\begin{array}{l}\text { Masih ditemukannya nelayan yang menggunak- } \\
\text { an bom dan racun dalam operasi penangkapan }\end{array}$ & 0.11 & 2 & 0.22 \\
\hline 3 & $\begin{array}{l}\text { Tren ukuran gurita yang tertangkap semakin } \\
\text { kecil }\end{array}$ & 0.10 & 2 & 0.20 \\
\hline 4 & $\begin{array}{l}\text { Tingginya tekanan dan upaya penangkapan gu- } \\
\text { rita }\end{array}$ & 0.10 & 2 & 0.20 \\
\hline \multirow[t]{3}{*}{5} & $\begin{array}{l}\text { Adanya potensi konflik yang terjadi dalam zo- } \\
\text { nasi daerah penangkapan }\end{array}$ & 0.08 & 2 & 0.16 \\
\hline & Jumlah & 0.53 & & 1.06 \\
\hline & Total & 1 & & 2.47 \\
\hline
\end{tabular}


Strategi pengelolaan perikanan gurita di Kabupaten Banggai Laut

Perikanan gurita di Kabupaten Banggai Laut ditentukan dengan melakukan analisis lanjutan terhadap hasil analisis matriks IFAS (Tabel 4) dan EFAS (Tabel 5). Hal ini dilakukan dengan mengembangkan matriks Internal-Eksternal (matriks IE) yang merupakan hasil pemetaan kuadran nilai total matriks IFAS dan EFAS. Hasil analisis dari tabel IFAS dan EFAS disajikan pada Gambar 2.

Hasil analisis faktor kekuatan diperoleh skor 1.69, faktor kelemahan diperoleh skor 0.94, faktor peluang diperoleh skor 1.42, faktor ancaman diperoleh skor 1.06. Strategi matriks IFAS dan matriks EFAS berada pada nilai 2.63 dan 2.47. Strategi pengelolaan perikanan gurita di Kabupaten Banggai Laut berada pada kuadran V (Gambar 2). Hal ini menunjukkan bahwa pengelolaan perikanan gurita dalam kondisi pertumbuhan dengan konsentrasi pada intergrasi horizontal atau stabilitas. Kondisi perikanan gurita di Kabupaten Banggai Laut memliki lebih banyak faktor kekuatan yang harus lebih ditingkatkan untuk mengatasi kelemaha n. Faktor kekuatan yang dimaksud yaitu dengan memanfaatkan gurita yang termasuk hasil tangkapan dominan di Kabupaten Banggai Laut. Faktor peluang harus lebih diprioritaskan kedepannya untuk mengatasi ancaman yang ada. Pemahaman dan informasi untuk pengelolaan sumberdaya gurita harus lebih ditingkatkan untuk mengatasi ancaman yang ada.

\section{Nilai Bobot IFAS}

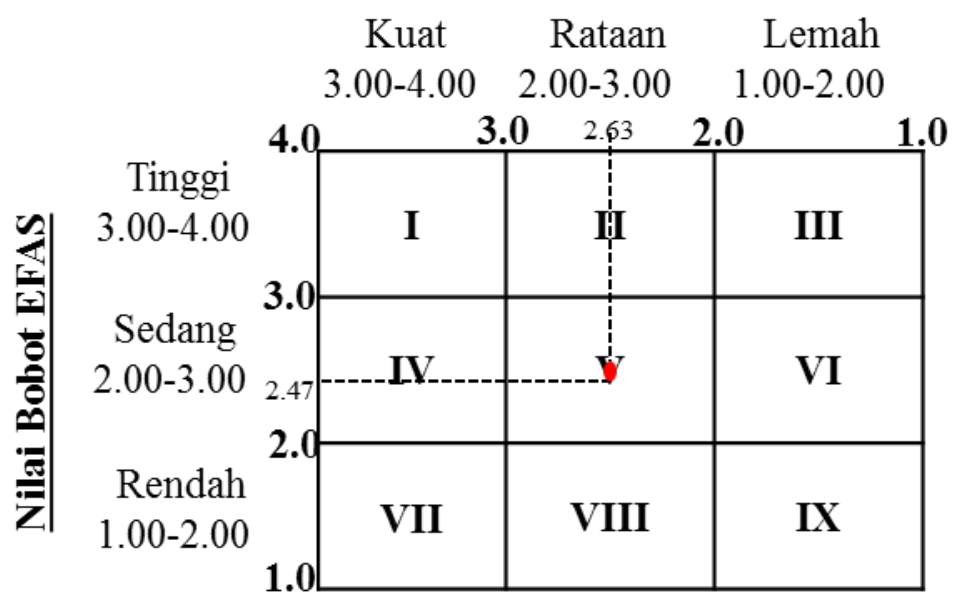

Gambar 2. Matriks IE perikanan gurita di Kabupaten Banggai Laut

Hasil matriks perbandingan antara faktor internal dan faktor eksternal diperoleh beberapa strategi. Opsi strategi kebijakan disusun berdasarkan matriks skor strategi SWOT dengan perpaduan faktor-faktor yang ada (Tabel 6). Opsi strategi dibagi berdasarkan SO, ST, WO, WT. Berikut merupakan opsi strategi pengelolaan perikanan gurita di Kabupaten Banggai Laut:

1) Strategi - SO, dengan opsi strategi: Memanfaatkan potensi gurita untuk memenuhi pasar ekspor dan peningkatan kerjasama dengan industri pengolahan ikan di Kabupaten Banggai Laut

Potensi sumber daya gurita yang terdapat di perairan Banggai Laut yang cukup besar. Namun belum sepenuhnya dimanfaatkan secara optimal oleh masyarakat nelayan. Hal ini dikarenakan armada penangkapan yang belum mendukung untuk menjangkau daerah penangkapan yang lebih jauh. Strategi pemanfaatan potensi perikanan sesuai dengan penelitian yang dilakukan oleh beberapa peneliti (Yahya et al. 2013; Nazdan et al. 2008). Potensi sumberdaya gurita di Kabupaten Banggai Laut berbeda dengan potensi perikanan gurita yang ada di daerah lain seperti di daerah Karimunjawa dan Gunung Kidul. Perbedaan dikarenakan produksi gurita Di Kabupaten Bangai Laut termasuk dalam potensi unggulan perikanan (DKP Banggai Laut 2016).

Pemanfaatan terhadap potensi gurita dapat dicapai melalui peningkatan kerjasama dengan industri pengolahan ikan yang ada di Kabupaten Banggai Laut. 
Tabel 6. Matrik SWOT strategi pengelolaan perikanan gurita

\begin{tabular}{|c|c|c|}
\hline & Kekuatan (S) & Kelemahan (W) \\
\hline \multirow[t]{4}{*}{ Faktor Internal } & $\begin{array}{l}\text { 1) Gurita termasuk hasil tang- } \\
\text { kapan dominan yang ter- } \\
\text { dapat di Kabupaten Banggai } \\
\text { Laut }\end{array}$ & $\begin{array}{l}\text { 1) Kapal dan alat tangkap } \\
\text { yang masih tradisional }\end{array}$ \\
\hline & $\begin{array}{l}\text { 2) Perikanan dan kelautan } \\
\text { telah memberikan kontribusi } \\
\text { ekonomi bagi pembangunan } \\
\text { daerah Kabupaten Banggai } \\
\text { Laut }\end{array}$ & $\begin{array}{l}\text { 2) Sumberdaya manusia } \\
\text { tenaga ahli perikanan } \\
\text { yang masih sedikit }\end{array}$ \\
\hline & $\begin{array}{l}\text { 3) Armada penangkapan gurita } \\
\text { yang termasuk ramah ling- } \\
\text { kungan }\end{array}$ & $\begin{array}{l}\text { 3) Masih minimnya kebi- } \\
\text { jakan dan pengawasan } \\
\text { terhadap nelayan skala } \\
\text { kecil }\end{array}$ \\
\hline & $\begin{array}{l}\text { 4) Harga gurita yang ekonomis } \\
\text { tinggi }\end{array}$ & $\begin{array}{l}\text { 4) Belum tersedianya } \\
\text { pelabuhan khusus } \\
\text { perikanan di Kabupaten } \\
\text { Banggai Laut }\end{array}$ \\
\hline Faktor Eksternal & $\begin{array}{l}\text { 5) Biaya bekal melaut yang } \\
\text { rendah }\end{array}$ & \\
\hline Peluang (O) & Strategi SO & Strategi WO \\
\hline $\begin{array}{l}\text { 1) Adanya perusahaan } \\
\text { pengolahan ikan di Kabu- } \\
\text { paten Banggai Laut }\end{array}$ & $\begin{array}{l}\text { 1) Pengembangan kerjasama } \\
\text { dengan industri pengolahan } \\
\text { ikan di Kabupaten Banggai } \\
\text { Laut }\end{array}$ & $\begin{array}{l}\text { 1) Peningkatan kualitas } \\
\text { SDM melalui pelatihan } \\
\text { dan pemberdayaan ne- } \\
\text { layan }\end{array}$ \\
\hline $\begin{array}{l}\text { 2) Potensi sumberdaya } \\
\text { gurita yang melimpah di } \\
\text { Perairan Banggai Laut }\end{array}$ & $\begin{array}{l}\text { 2) Memanfaatkan potensi gu- } \\
\text { rita untuk memenuhi per- } \\
\text { mintaan pasar ekspor }\end{array}$ & $\begin{array}{l}\text { 2) Membangun pelabuhan } \\
\text { perikanan di Kabupaten } \\
\text { Banggai Laut }\end{array}$ \\
\hline \multicolumn{3}{|l|}{$\begin{array}{l}\text { 3) Dukungan dan komitmen } \\
\text { pemerintah Banggai Laut } \\
\text { terhadap sektor perikanan } \\
\text { dan kelautan }\end{array}$} \\
\hline \multicolumn{3}{|l|}{$\begin{array}{l}\text { 4) Pengembangan perikanan } \\
\text { gurita akan membuka } \\
\text { peluang kesempatan kerja } \\
\text { di bidang perikanan }\end{array}$} \\
\hline Ancaman (T) & Strategi ST & Strategi WT \\
\hline $\begin{array}{l}\text { 1) Masih kurangnya infor- } \\
\text { masi dan pemahaman ne- } \\
\text { layan terkaitpengelolaan } \\
\text { sumberdaya gurita }\end{array}$ & $\begin{array}{l}\text { 1) Menetapkan aturan dan } \\
\text { sanksi yang tegas terhadap } \\
\text { nelayan yang melakukan il- } \\
\text { legal fishing }\end{array}$ & $\begin{array}{l}\text { 1) Membuat aturan terkait } \\
\text { bobot ukuran gurita } \\
\text { yang boleh ditangkap }\end{array}$ \\
\hline $\begin{array}{l}\text { 2) Masih ditemukan nelayan } \\
\text { yang menggunakan bom } \\
\text { dan racun dalam operasi } \\
\text { penangkapan }\end{array}$ & $\begin{array}{l}\text { 2) Membatasi armada penang- } \\
\text { kapan gurita yang berop- } \\
\text { erasi di Kabupaten Banggai } \\
\text { Laut }\end{array}$ & $\begin{array}{l}\text { 2) Pengawasan daerah } \\
\text { penangkapan ikan lebih } \\
\text { ditingkatkan }\end{array}$ \\
\hline \multicolumn{3}{|l|}{$\begin{array}{l}\text { 3) Tren ukuran gurita yang } \\
\text { tertangkap semakin kecil }\end{array}$} \\
\hline \multicolumn{3}{|l|}{$\begin{array}{l}\text { 4) Tingginya tekanan dan } \\
\text { upaya penangkapan gu- } \\
\text { rita }\end{array}$} \\
\hline $\begin{array}{l}\text { 5) Adanya potensi konflik } \\
\text { yang terjadi terkait zonasi } \\
\text { daerah penangkapan }\end{array}$ & & \\
\hline
\end{tabular}


Hal ini dikarenakan gurita merupakan komoditi perikanan ekspor. Penelitian Nurdyana et al. 2013; Ismail et al. 2015; Listiani 2013 menyebutkan perlu adanya peningkatan kerjasama dengan industri pengolahan ikan. Peningkatan kerjasama dapat meningkatkan kesempatan lapangan pekerjaan di bidang perikanan. Selain itu dengan adanya kerjasama memudahkan koordinasi pemerintah dan pengusaha perikanan.

2) Strategi - ST, dengan opsi strategi: Menetapkan aturan dan sanksi yang tegas terhadap nelayan yang melakukan illegal fishing dan Membatasi armada dan alat penangkapan gurita yang beroperasi di Kabupaten Banggai Laut

Strategi yang didapat yaitu Kebijakan untuk membatasi armada dan alat penangkapan gurita yang beroperasi di Kabupaten Banggai Laut. Batasan armada diperlukan mengingat semakin tinggi nya intensitas penangkapan dan upaya penangkapan yang dilakukan. Menurut Huffard et al. 2012, Armada penangkapan nelayan perikanan skala kecil meningkat lebih dari $40 \%$ selama 10 tahun terakhir. Penetapan batasan armada penangkapan gurita juga dilakukan di daerah lain seperti Korea Selatan dan Moroko (Kim 2008; Veguilla 2009; Faraj dan Bez 2007). Dengan adanya batasan yang dilakukan diharapkan dapat meminimumkan intensitas penangkapan gurita di Kabupaten Banggai Laut.

Pelanggaran terkait illegal fishing terjadi sebanyak 2-4 kali pertahun di Perairan Kabupaten Banggai Laut (Adel et al. 2017). Hal ini menyebabkan adanya potensi kerusakan habitat dan ekosistem perairan. Aturan dan sanksi yang tegas perlu dilaksanakan terkait penangkapan yang tidak ramah lingkungan. Penggunaan alat tangkap destruktif atau illegal yang sudah diamanatkan dalam UU No.45/2009 seharusnya sudah ditaati. Dengan adanya peraturan dan sanksi yang dilaksanakan maka akan mengurangi penangkapan yang tidak ramah lingkungan.

3) Strategi - WO, dengan opsi strategi: Peningkatan kualitas SDM melalui pelatihan dan pemberdayaan nelayan, serta membangun pelabuhan perikanan di Kabupaten Banggai Laut

Strategi pelaksanaan peningkatan kualitas SDM diarahkan kepada pegawai Dinas Kelautan dan Perikanan Kabupaten Banggai Laut dan nelayan. Peningkatan kualitas dilakukan dengan pembinaan formal dan non formal. Selain itu diperlukan pemberdayaan nelayan untuk menjaga kelestarian sumberdaya gurita. Hal ini karena nelayan yang langsung bersentuhan dengan kegiatan penangkapan gurita. Pemberdayaan nelayan dengan melakukan pelatihan dan pembinaan tentang penggunaan alat tangkap yang ramah lingkungan (Puansalaing et al. 2012; Nurdyana et al. 2013) dan penanganan kualitas mutu hasil tangkapan gurita (Yahya et al. 2013. Pelatihan dan pemberdayaan nelayan diharapkan dapat memaksimalkan produksi gurita yang terdapat di Kabupaten Banggai Laut.

Kabupaten Banggai Laut belum memiliki pelabuhan perikanan. Hal tersebut sudah seharusnya menjadi perhatian stakeholder setempat dikarenakan pelabuhan perikanan diperlukan dalam rangka menunjang usaha motorisasi serta pengembangan ekonomi perikanan secara menyeluruh, terutama untuk menunjang perkembangan industri perikanan baik hulu maupun hilir, sehingga diharapkan akan tercapai pemanfaatan sumberdaya perikanan yang seimbang, merata dan proposional (Yuspardianto, 2006). Selain itu pelabuhan perikanan mempunyai tugas melaksanakan fasilitas produksi, penanganan dan pengolahan, fasilitas pengendalian dan pengawasan mutu, pemasaran hasil perikanan, fasilitas dan melakukan pembinaan masyarakat nelayan (KEPMEN-KP No.34/2004). Pembangunan pelabuhan perikanan sangat dibutuhkan untuk memudahkan koordinasi dan pengawasan kualitas hasil tangkapan perikanan di Kabupaten Banggai Laut. Pembangunan perikanan diharapkan dapat meningkatkan kualitas mutu hasil tangkapan gurita dan perekonomian daerah Banggai Laut. Selain itu dengan adanya pelabuhan perikanan dapat memaksimalkan pendataan perikanan dan kelautan.

4) Strategi - WT, dengan opsi strategi: Membuat aturan terkait bobot ukuran gurita yang boleh ditangkap dan Pengawasan daerah penangkapanikan

Pemerintah beserta stakeholder perikanan diharapkan membuat aturan terkait bobot ukuran gurita yang boleh ditangkap. Tren bobot ukuran gurita di 
Kabupaten Banggai Laut diperlukan untuk mengurangi tren ukuran gurita yang tertangkap semakin kecil. Penetapan bobot ukuran yang boleh ditangkap telah diterapkan pada lobster, kepiting dan rajungan (PERMEN-KP No.56/2016), namun belum ada untuk perikanan gurita di Indonesia. Penetapan bobot gurita telah dilakukan di Spanyol dengan maksimum $1.000 \mathrm{gr}$, namun untuk jenis gurita yang berbeda (Fernandez \& Rueda 2007). Setelah penetapan bobot kemudian dilakukan sosialisasi dengan membuat buku saku terkait hasil tangkapan perikanan yang boleh ditangkap (Dinas Industri Primer dan Pembangunan Daerah Australia Barat 2017: Dinas Industri Primer, Taman, Air dan Lingkungan Tasmania 2017). Strategi ini diharapkan memberikan dampak yang positif untuk keberlanjutan sumberdaya gurita.

Strategi pengawasan daerah penangkapan perlu dilakukan mengingat adanya potensi konflik yang terjadi diakibatkan nelayan asing atau non lokal yang menangkap gurita di Kabupaten Banggai Laut (Puansalaing et al. 2012). Selain itu pengawasan daerah penangkapan untuk nelayan yang melakukan secara illegal fishing. Pengawasan daerah penangkapan ikan untuk menjaga kelestarian sumberdaya gurita di Kabupaten Banggai Laut.

\section{KESIMPULAN DAN SARAN}

\section{Kesimpulan}

Strategi pengelolaan perikanan gurita di Kabupaten Banggai Laut dilakukan dengan 1) Strategi SO dengan opsi strategi: Pengembangan kerjasama dengan industri pengolahan ikan dan memanfaatkan potensi perikanan gurita, 2) Strategi ST dengan opsi strategi: Menetapkan aturan dan sanksi yang tegas terkait nelayan yang melakukan illegal fishing dan membatasi armada penangkapan ikan, 3) Strategi WO dengan opsi strategi: peningkatan kualitas SDM dan membangun pelabuhan perikanan, 4) Strategi WT dengan opsi strategi: membuat aturan terkait bobot gurita dan pengawasan daerah penangkapan ikan.

\section{Saran}

Penelitian lebih lanjut dengan menggunakan Analysis Hierarcy Proccess (AHP) untuk menentukan prioritas kebijakan dalam pengelolaan perikanan gurita di Kabupaten Banggai Laut

\section{DAFTAR PUSTAKA}

Adel Y, Yovitner, Rahardjo MF. 2016. Pengelolaan Sumber Daya Perikanan Banggai Cardinalfish (Pterapogonkauderni, Koumans 1933) Dengan Pendekatan Ekosistem (Studi Kasus Pulau Banggai Kabupaten Banggai Laut). Jurnal Ilmu Pertanian Indonesia (JIPI). Vol. 21 (3): 186-194.

Arikunto S. 2009. Prosedur Penelitian Suatu Pendekatan Praktik. Edisi Revisi 6. Jakarta (ID): Rineka Cipta.

Bachtiar N, Harahap N, Riniwati H. 2013. Strategi Pengembangan Pemasaran Ikan Sidat (Anguilla bicolor) di Unit Pengelola Perikanan Budidaya (UPPB) Desa Deket, Kecamatan Deket, Kabupaten Lamongan, Jawa Timur. API Student Journal. 1(1): 29-36.

[DKP] Dinas Perikanan dan Kelautan Kabupaten Banggai Laut. 2016. Profil Kelautan dan Perikanan Kabupaten Banggai Laut 2016.

Department of Primary Industries and Regional Development Western Australia 2017. Recreational Fishing Guide 2017/2018. Government Of Western Australia. 43 pp. Department of Primary Industries, Parks, Water and Environment Tasmanian 2017. Recreational Sea Fishing Guide 20162017. Tasmanian Government. 80 pp.

Faraj A, Bez N. 2007. Spatial considerations for the Dakha stock of Octopus vulgaris: indicators, patterns and fisheries impacts. ICES Journal of Marine Science, 64: 1820-1828.

Fernandez, Rueda P. 2007. Octopus vulgaris (Mollusca: Cephalopoda) fishery management assessment in Asturias (north - west Spain). Fisheries Research. 83 (2-3): 351-354.

Huffard CL, Erdmann MV, Gunawan TRP. 2012. Geographic Priorities for Marine Biodiversity Conservation in Indonesia. Ministry of Marine Affairs and Fisheries and Marine Protected Areas Governance Program. Jakarta (ID). $105 \mathrm{pp}$.

Ismail, Anggoro DS, Pramonowibowo. 2015. Strategi Pengembangan Pelabuhan Perikanan Samudera (PPS) Kendari, Kota Kendari, Sulawesi Tenggara. Journal of Fisheries Resources 
Utilization Management and Technology. 4(4): 67-77.

[KKP] Kementerian Kelautan dan Perikanan. 2004. Surat Keputusan Kementerian Menteri Nomor 34 tahun 2004 tentang Fungsi Pelabuhan Perikanan. Jakarta (ID).

[KKP] Kementerian Kelautan dan Perikanan. 2016. Peraturan Menteri Nomor 56 tahun 2016 tentang Larangan Penangkapan dan/atau Pengeluaran Lobster (Panulirus spp.), Kepiting (Scylla spp.), dan Rajungan (Portunus spp.) dari Wilayah Negara Republik Indonesia. Jakarta (ID).

Kim DH. 2008. Optimal economic fishing efforts in Korean common octopus. Octopus minor trap fishery. Fisheries Science. 74(6): 1215-1221.

Listiani N. 2013. Penerapan Standar Ekspor Gurita dan Ikan Teri Perusaaan Perikanan di Kendari. Buletin Ilmiah Litbang Perdagangan. Vol 7 (1): 91110.

Nazdan, Setiawan B, Sukandar D. 2008. Analisis Potensi dan Pengelolaan Perikanan dalam Perspektif Ketahanan Pangan di Wilayah Pesisir Kabupaten Lampung Barat. Jurnal Gizi dan Pangan. 3(3): 149-155.

Nurdin E, Nugraha B. 2008. Penangkapan Tuna dan Cakalang dengan Menggunakan Alat Tangkap Pancing Ulur (Hand line) yang Berbasis di Pangkalan Pendaratan Ikan Pondok Dadap Sendang Biru, Malang. Bawal Widya Riset Perikanan Tangkap. Vol 2 (1): 25-31.

Nurdyana E, Rosyid A, Boesono H. 2013. Strategi Peningkatan Pemanfaatan Fasilitas Dasar dan Fungsional Pelabuhan Perikanan Pantai (PPP) Tegalsari Kota Tegal. Journal of Fisheries Resources Utilization Management and Technology. 2(2): 3545.

Puansalaing DM, Wenno J, Kumajas HJ. 2012. Analisis Strategi Pengembangan Perikanan Pucat Cincin di Kecamatan
Tuminting Kota Manado Provinsi Sulawesi Utara. Jurnal Ilmu dan Teknologi Perikanan Tangkap. 1(2): 43-49.

Rangkuti F. 2009. Analisis SWOT: Teknik Membedah Kasus Bisnis. Jakarta (ID):

PT. Gramedia Pustaka Utama. 188 hlm.

Salas S, Sumaila UR, Pitcher T. (2004). Shortterm Decision of Small-scale Fishers Selecting Alternative Target Species: a Choice Model. Can .J. Fish. Aquat. Sci. 61: 374-383.

Satori D, Komariah A. 2009. Metodologi penelitian kualitatif. Bandung (ID): Alfabeta C.V.

Suherman A. 2011. Formulasi Strategi Pengembangan Pelabuhan Perikanan Nusantara Pengambengan Jembrana. Marine Fisheries 2 (1): 87-99.

Sulistyaningsih RK, Barata A, Siregar K. 2011. Perikanan Pancing Ulur Tuna di Kedonganan, Bali. Jurnal Penelitian Perikanan Indonesia. 17 (3): 185-191.

Suyedi R. 2007. Analisis Pengembangan Perikanan Tangkap di Kota Bengkulu. [Tesis]. Bogor (ID): Institut Pertanian Bogor.

[UU] Republik Indonesia. 2009. UndangUndang No. 45 Tentang Perikanan dan Kelautan. Jakarta (ID).

Veguilla V. 2009. The exploitation of octopuses in Morocco: conflicts and collective action. Politique Africaine, 116: 43-62.

Yuspardianto. 2006. Studi Fasilitas Pelabuhan Perikanan dalam Rangka Pengembangan Pelabuhan Perikanan Samudera Bungus Sumatera Barat. Journal of Mangrove dan Pesisir. 4(1): 47-55.

YahyaE. 2013. Tingkat Pemanfaatan Fasilitas Dasar dan Fungsional dalam Strategi Peningkatan Produksi di Pelabuhan Perikanan Pantai Tegalsari Kota Tegal Jawa Tengah. Journal of Fisheries Resources Utilization Management and Technology. 2(1): 56-65. 